\title{
TAYLOR RULE AND \\ DISCRETIONARY REGIMES IN THE \\ UNITED STATES: EVIDENCE FROM A $k$-STATE MARKOV REGIME-SWITCHING MODEL
}

\author{
JOSEPh D. Alba \\ Nanyang Technological University \\ Peiming Wang \\ Auckland University of Technology
}

We examine U.S. monetary policies from 1973 to 2014 with the Taylor rule as a benchmark by utilizing a $k$-state Markov regime-switching model in which the number and the periods of the regimes are endogenously determined. The model relates the federal funds rate to real time output gaps and inflation forecast. It endogenously identifies the periods of Taylor rule regime and discretionary regimes, consistent with the U.S. experience. The Taylor rule regime also coincides with periods of lower variability in inflation and in real GDP growth.

Keywords: Markov Model, Taylor Rule

\section{INTRODUCTION}

To assess monetary policy, particularly in the United States, the Taylor rule [Taylor (1993)] has been used as a benchmark. The Taylor rule prescribes increasing the policy rate whenever inflation increases over the target inflation rate and output increases over potential output. A large body of literature examines whether the Fed followed or deviated from the Taylor rule during the past decades. The early literature on the matter exogenously determines the various U.S. monetary policy regimes according to the duration of the terms of the chairmen of the Federal Reserve Bank. Taylor (1999) and Clarida et al. (2000) use revised data to examine Fed policies during the pre-Volker and Volker-Greenspan eras, and they find that the Taylor principle holds only during the Volker-Greenspan era. Orphanides (2004) uses real time data available to policy makers when they make decisions, and he finds that the Taylor principle is satisfied during the pre-Volker and VolkerGreenspan eras.

\footnotetext{
We are grateful to two anonymous referees for their helpful comments. Address correspondence to: Joseph D. Alba, HSS-04-79, School of Humanities and Social Sciences, Nanyang Technological University, Singapore 639798; e-mail: ajoalba@ntu.edu.sg.
} 
More recent literature uses models that endogenously determine the periods when the Taylor principle holds. Boivin (2006) uses real time data and the timevarying parameter (TVP) model on a forward-looking Taylor rule. He finds that the response of U.S. monetary policy to forecast inflation was strong from 1970 until 1973, declined drastically from 1974 until 1982, and was strong again from mid-1980 through the 1990s. In contrast, he finds that the response of monetary policy to real economic activity weakened from the 1970s through the 1980s. His evidence suggests that the Taylor rule may not hold from 1974 to 1982 . Kim and Nelson (2006) use ex post data and the TVP model and also find that the policy response to forecast inflation was weak in the 1970s but strengthened from the early 1980s to the 1990s. They also find that the response of federal funds rate to real GDP gap was significantly positive from 1974 to 1979 , even though it was not significantly different from zero in the 1980 s.

Davig and Leeper (2006, 2011) use a Markov regime-switching Taylor rule specification that includes the inflation, the output gaps, and the variance, in which four regimes are allowed: namely, active monetary policy (the inflation coefficient is greater than one) with high and low variances and passive monetary policy (the inflation coefficient is less than one) with high and low variances. They use ex post data for the United States from 1948 to 2008 and find monetary policy to be passive from 1948 to 1979 , except from 1959 to 1960 , and active from 1980 to 2008, except for 1991-1994 and 2001-2008. Castelnuovo et al. (2014) consider a two-state Markov regime-switching model with a Taylor rule specification with a time-varying inflation target. Using revised data, they identify the 1960s, 1980s, and mid-1990s to 2007 as active monetary policy regimes and the 1970s and early 1990 s as passive monetary policy regimes.

Murray et al. (2015) estimate a two-state Markov regime-switching model for a forward-looking Taylor rule using real time inflation forecast and real time output gaps from 1965Q4 to 2007Q4. ${ }^{1}$ They find that the Taylor rule did not hold during 1973Q1-1975Q1 and 1979Q4-1985Q1, but it held during 1965Q41972Q4, 1975Q2-1979Q3, and 1985Q2-2007Q4. Nikolsko-Rzhevskyy (2013) [henceforth, NPP (2013)] also use a two-state Markov regime-switching model of deviations from Taylor rule, in which the deviations are defined as the absolute values of the difference between the federal funds rate and the implied interest rate of the Taylor (1993) rule. ${ }^{2}$ The two states in the Markov regime-switching model are high and low deviations from the Taylor rule, with the former implying that the Taylor rule does not hold and the latter implying that it does. They find that the Taylor rule regime holds during 1969Q1 to 1974Q3, 1986Q2 to 2001Q1, and 2006Q3 to 2007Q4, whereas the discretionary regime holds during 1965Q4 to 1968Q4, 1974Q4 to 1986Q1, 2001Q2 to 2006Q2, and 2008Q1 to 2008Q4.

We contribute to the literature by determining endogenously the U.S. monetary regimes from 1973Q3 to 2014Q1, with the Taylor rule as a benchmark. ${ }^{3}$ We utilize a $k$-state Markov regime-switching model that relates the federal funds rate to real time output gaps and the real time GDP deflator inflation forecast. More specifically, for a given value of $k$, we estimate the maximized log-likelihood, 
the value of the Schwarz (1978) criterion, and the parameters of the model. Then we use the Schwarz criterion to choose the number of regimes, $k$, of the Markov regime-switching model. The Schwarz criterion leads to ta three-state Markov regime-switching model with one of the three regimes specified as the forward-looking Taylor (1993) rule, in which the target interest rate equals one plus 1.5 times inflation forecast plus 0.5 times output gaps. In contrast, the other two regimes have inflation forecast and output gap coefficients estimated by the Markov regime-switching model based on the observed data. The model specifies one of the three regimes for a given period, based on the highest value of the smoothing probabilities among the three regimes. Furthermore, the estimates of the conditional variances of the federal funds rate and the plots of the implied interest rates of the other two regimes that deviate from the Taylor rule show that one regime has lower and the other regime has higher conditional variances and implied interest rates than the corresponding figures for the Taylor rule. Hence, we refer to the three regimes as the "Taylor rule" regime (regime 1), the "low" discretionary regime (regime 2), and the "high" discretionary regime (regime 3). ${ }^{4}$

We consider two commonly used measures of the output gaps from 1973Q3 to 2014 Q1 in examining monetary policy regimes in the United States. The first measure calculates output gaps as percent deviations of real time GDP from its quadratic trend ("quadratic" output gaps). The second measure combines data on output gaps calculated from its quadratic trend, data from the Federal Reserve's Greenbook (GB) database, and data on output gaps calculated as deviations from Congressional Budget Office (CBO) estimates of potential output ("quadratic+GB+CBO" output gaps).

Using the quadratic output gaps and inflation forecast as regressors, the threestate Markov regime-switching model determines 1973Q3 to 1980Q3 to be mostly low discretionary regime, except for 1973Q3 to 1974Q3 and 1979Q4 to 1980Q1, when the Taylor rule holds; 1980Q4 to 1986Q4 to be high discretionary regime; 1987Q1 to 1992Q1 to be Taylor rule regime; 1992Q2 to 1994Q1 to be low discretionary regime; 1994Q2 to 2001Q1 to be Taylor rule regime; 2001Q2 to 2005Q4 to be low discretionary regime; 2006Q1 to 2007Q4 to be Taylor rule regime; and 2008Q1 to 2014Q1 to be low discretionary regime. We identify mostly the same periods of the Taylor rule regime as NPP (2013), except 1986Q21986Q4, which we identify as high discretionary regime, and 1991Q2-1994Q1, which we identify as low discretionary regime. Whereas NPP (2013) identify the non-Taylor-regime periods as high-deviation discretionary periods, we identify these periods either as low discretionary regime (1974Q4 to 1979Q3, 1980Q3 to 1980Q3, 2001Q2 to 2005Q4, and 2008Q1 to 2008Q4) or high discretionary regime (1980Q2 to 1986Q1). They also identify 1979Q4 to 1980Q1 as a high-deviation discretionary period, but we identify the same period as a Taylor rule period.

Using the quadratic $+\mathrm{GB}+\mathrm{CBO}$ output gaps and inflation forecast as regressors, the three-state Markov regime-switching model determines the same regimes from 1973Q3 to 1986Q4 as the specification with quadratic output gaps and inflation forecast as regressors. For the period 1987Q1-2008Q1, the results of the 
Markov regime-switching model show that the high discretionary regime holds until 1989Q4 (from 1980Q4), followed by the Taylor rule regime from 1990Q1 to 2008Q1. The results also show that the low discretionary regime holds from 2008Q2 to 2014Q1. In contrast, Murray et al. (2015) find a "destabilizing" Taylor rule from 1979Q4 to 1985Q1 and a "stabilizing" Taylor rule from 1985Q2 to 1989Q4. Our findings are broadly consistent with the findings of Boivin (2006) and Kim and Nelson (2006) using forward-looking TVP models. To reiterate, Boivin finds a strong U.S. monetary policy response to inflation until 1974, a weak response from 1974 to 1982, and a strong response again from the mid1980 s through the 1990s, but a weak monetary policy response to real economic activity from the 1970s through the 1980s. Kim and Nelson find a weak monetary policy response to expected inflation with a significantly positive effect of the federal funds rate on real GDP gap in the 1970s, but a strong response to expected inflation with insignificant effect of federal funds rate on real GDP in the 1980s.

With the regimes determined from the model, we calculate the average inflation variability and real GDP growth variability of the three regimes. We find that the average inflation and real GDP growth variability are lower during the Taylor rule regime than during the two discretionary regimes. ${ }^{5}$

The paper is organized as follows: Section 2 discusses the $k$-state Markov regime switching model, the estimation methods, and the data; Section 3 discusses the empirical results; and Section 4 gives the conclusions.

\section{METHODOLOGY AND DATA}

\subsection{Markov Regime-Switching Model}

The monetary rule for central banks proposed by Taylor (1993) is specified as

$$
i_{t}=\pi_{t}+\phi\left(\pi_{t}-\bar{\pi}\right)+\gamma y_{t}+r^{*},
$$

where $i_{t}$ is the target short-term interest rate, $\pi_{t}$ is the inflation rate, $\bar{\pi}$ is the target inflation rate, $y_{t}$ is the output gap, and $r^{*}$ is the equilibrium real interest rate. The output gap is the actual real GDP minus the estimated potential real GDP over the potential real GDP, multiplied by 100 . Inflation is the year-on-year percentage change in aggregate prices. The target short-term interest rate is equal to the actual short-term interest rate, assuming the central bank achieves its target interest rate within the period. According to Taylor (1993), $\phi=\gamma=0.5$ and $\bar{\pi}=r^{*}=2 \%$ for the United States. Furthermore, because the Fed is assumed to be forward-looking, we adopt the forward-looking Taylor rule, so equation (1) becomes

$$
i_{t}=1+1.5 E_{t} \pi_{t+h}+0.5 y_{t},
$$

where $E_{t} \pi_{t+h}$ is the expectation at $t$ of the inflation at $t+h$.

Whether the Fed follows the Taylor rule at time $t$ depends on the economic conditions at that time. As the economic conditions change over time, the Fed may deviate from the Taylor rule so that the nominal interest rate is no longer 
determined by equation (2). Hence, in the $k$-state Markov regime-switching model, let the indicator $S_{t}$ represent the state of the monetary policy at time $t$, with $S_{t}=1$ for the state in which the Fed implements the Taylor rule and with $S_{t}=j(j>1)$ for the state in which the Fed deviates from the Taylor rule. The nominal interest rate is determined by

$$
i_{t}=\beta_{0, S_{t}}+\beta_{1, S_{t}} E_{t} \pi_{t+h}+\beta_{2, S_{t}} y_{t}+\varepsilon_{t},
$$

where $\left(\beta_{0, S_{t}}, \beta_{1, S_{t}}, \beta_{2, S_{t}}\right)=(1,1.5,0.5)$ if $S_{t}=1$; otherwise $\left(\beta_{0, S_{t}}, \beta_{1, S_{t}}, \beta_{2, S_{t}}\right) \neq$ $(1,1.5,0.5)$; and $\varepsilon_{t} \mid S_{t}=j \sim N\left(0, \sigma_{j}^{2}\right)$. The dynamics of the state is governed by a $k$-state first-order Markov chain with transition probabilities defined by

$$
P\left(S_{t}=j \mid S_{t-1}=i\right)=p_{i j} \text {, where } i, j \in\{1, \ldots, k\},
$$

Under this setup, the $k$ possible states (or regimes) of the monetary policies are characterized by the $k$ possible specifications that relate the interest rate to inflation forecast and output gaps, each corresponding to a particular state of monetary policy. If $k=1$, the regression coefficients $\left(\beta_{0,1}, \beta_{1,1}, \beta_{2,1}\right)$ are estimated instead of fixed at $(1,1.5,0.5)$. If $k>1$ and the Fed employs the Taylor rule in a period, the interest rate for that period is expected to be determined by equation (2); and if the Fed deviates from the Taylor rule, the interest rate is expected to relate to the inflation forecast and output gaps with regression coefficients different from equation (2). However, at any point in time, the Fed does not reveal to the public whether or not it follows the Taylor rule, so the public can only make inferences regarding the state or regime of monetary policy at time $t$ based on observed information. Hence, the state variable $S_{t}$ is a latent variable in the Markov regimeswitching model.

We implement our method in two steps. First, for a given value of $k$, we obtain the maximized log-likelihood, the value of the Schwarz (1978) criterion for model selection, as well as the maximum likelihood estimates of the model parameter vector $\theta=\left\{\beta_{0, j}, \beta_{1, j}, \beta_{2, j}, \sigma_{j}^{2}, p_{i j} ; i, j=1, \ldots, k\right\}$ with quarterly data $Z^{T}=\left\{\left(i_{t}, \pi_{t+h}, y_{t}\right) ; 1, \ldots T\right\}$ via the expectation-maximization (EM) algorithm using the method described in Hamilton (1994, Chap. 4). Second, we determine the number of regimes, $k$, by the Schwarz criterion defined, as -2 $\log (L)+n \log (T)$, where $L$ refers to the likelihood under the fitted model, $T$ is the total number of observations, and $n$ is the number of free parameters to be estimated in the model. Note that $n=4,7,15$, and 25 for $k=1,2,3$, and 4, respectively. As shown in Leroux (1992), the maximum likelihood estimates derived from the two-step estimation procedure are consistent and asymptotically normal. ${ }^{6}$

Based on the selected model, we then carry out inference about the state variable $S_{t}$ for each quarter $t$, with the smoothing probability defined by

$$
P\left(S_{t}=j \mid Z^{T}, \hat{\theta}\right), j=1, \ldots, k \text { and } t=1,2, \ldots, T .
$$


Specifically, quarter $t$ is identified with regime $j$ if the smoothing probability at time $t$ for regime $j$ has the highest value among the $k$ smoothing probabilities for that quarter. For example, quarter $t$ is identified with the Taylor rule regime if the probability of being in that regime, $P\left(S_{t}=1 \mid Z^{T}, \hat{\theta}\right)$, exceeds the smoothing probability for any other regime, i.e., $P\left(S_{t}=1 \mid Z^{T}, \hat{\theta}\right)>P\left(S_{t}=j \mid Z^{T}, \hat{\theta}\right)$ for any $j>1$.

Under the Taylor rule, the nominal interest rate is expected to respond to divergences of actual inflation rates from target inflation rates and of actual real GDP from potential real GDP as specified by equation (2). This may suggest an association between monetary regimes and the variability of inflation or of real GDP growth. Thus, we calculate and compare the average variability of inflation and of real GDP growth for each regime. We use two measures of inflation: GDP deflator inflation, as defined above, and consumer price index (CPI) inflation, which is the year-over-year percentage change in quarterly CPI. ${ }^{7}$ Real GDP growth is calculated as the quarterly change in real GDP. We measure inflation (real GDP growth) variability for quarter $t$, denoted as $v_{t}$, as $v_{t}=\left(r_{t-1}^{2}+r_{t-2}^{2}+r_{t-3}^{2}+r_{t-4}^{2}\right) / 4$, where $r_{t}$ is the change in inflation (real GDP growth) from quarter $t-1$ to quarter $t$. The average variability for a particular regime is the average of $v_{t}$ over the periods of the regime.

\subsection{The Data}

Data on output gap, inflation, and effective federal funds rate are downloaded from Alex Nikolsko-Rzhevskyy's Website. ${ }^{8}$ We use two measures of the output gap from the data set: the real time quadratic output gap and the real time quadratic $+\mathrm{GB}+\mathrm{CBO}$ output gap. The quadratic output gap is the percentage deviation of real time GDP from the quadratic trend. As discussed in NPP (2013), the quadratic trend is estimated beginning in 1947Q1 until the vintage year. The first vintage year is 1965Q4 and the last vintage year is 2010Q2. so quadratic output gap data from the data set are from 1965Q4 to 2010Q2. ${ }^{9}$ Following this procedure and using up-to-date real time GDP data from the Fed, we extend the quadratic output gap series to 2014Q1.

The quadratic $+\mathrm{GB}+\mathrm{CBO}$ output gap series augments the output gaps from the Federal Reserve Bank's Greenbook data set, which only covers 1987Q1 to 2007Q4, with output gap estimates based on quadratic detrending of real time real GDP from 1965Q4 to 1986Q4 and with estimates based on the potential real GDP published by the Congressional Budget Office (CBO) from 2008Q1 to 2010Q2. ${ }^{10}$ We extend the quadratic+GB+CBO output gap series to 2014Q1, using recently available real time real GDP data from the Fed and the potential real GDP data from the CBO.

We also use from Nikolsko-Rzhevskyy's data set the real time GDP deflator inflation forecast and the effective federal funds rate. We only consider the real time GDP deflator inflation forecast and not real time GDP deflator inflation because of the common belief that the Fed is forward-looking in formulating 
monetary policies. Real time GDP deflator inflation forecast data are averages of four consecutive quarters of the inflation forecast from the Greenbook database (1973Q3 to 2007Q4) and the Survey of Professional Forecasters (SPF) (2008Q12010Q2) database. ${ }^{11}$ We update the data on GDP inflation forecast and effective federal funds rate to 2014Q1 using data from Federal Reserve Bank websites.

We use real time quadratic output gaps and the quadratic $+\mathrm{GB}+\mathrm{CBO}$ output gaps to consider the possibility of spurious evidence of regime switches arising from splicing of the data. ${ }^{12}$ As mentioned earlier, the quadratic $+\mathrm{GB}+\mathrm{CBO}$ output gaps are spliced from real time quadratic output gaps (1965Q4-1986Q4), the Greenbook output gaps (1987Q1-2007Q4), and the CBO output gaps (2008Q12014Q1). In contrast, the real time quadratic output gap data-which have the same output gap observations from 1965Q4 to 1986Q4 as the quadratic+GB+ CBO output gaps - are continuous estimates using the quadratic trend of real time GNP/GDP from 1965Q4 to 2010Q2 extended to 2014Q1 using NPP's (2013) procedure. In addition, the real time GDP deflator inflation forecast data are continuously available at the Greenbook data set from 1973Q3 to 2007Q4 and spliced only with data from SPF from 2008Q1 to 2014Q1. To examine the possibility of spurious evidence of regime switches from spliced data, we compare the periods of the regime switches using the two measures of output gaps from 1973Q3 to 2007Q4. ${ }^{13}$

For comparison of variability of inflation and real GDP growth among the various regimes, we use quarterly revised data on percentage changes over the corresponding quarter of the previous year of the GDP deflator and of the CPI (all items) and on percent changes in real GDP obtained from the International Financial Statistics.

\section{EMPIRICAL RESULTS}

We endogenously determine the Federal Reserve Bank's monetary policy regimes from 1973Q3 to 2014Q1 using the $k$-state Markov regime-switching model with two data sets. The first data set includes quarterly values of the real time quadratic output gap together with quarterly federal funds rates and real time GDP deflator inflation forecasts, whereas the second data set replaces the data on output gap in the first data set with the data on real time quadratic $+\mathrm{GB}+\mathrm{CBO}$ output gaps.

For each value of $k(>1)$, we fitted each of the two data sets to the $k$-state Markov regime switching model to obtain the maximized log-likelihood and the value of the Schwarz criterion. For $k=1$, we fitted the data to the linear regression model to estimate the coefficients $\left(\beta_{0,1}, \beta_{1,1}, \beta_{2,1}\right)$ from equation (3). Table 1 reports the results of the two data sets for $k=1,2,3$, and 4 . For both data sets, the Schwarz criterion decreases from $k=1$ until $k=3$ and then rises at $k=4$. Because the Schwarz criterion begins to increase after $k=3$, we consider only up to $k=$ 4. Hence, the Schwarz criterion leads to the selection of the three-state Markov regime-switching model, as it has the smallest value for the criterion among the four models. 
TABLE 1. Maximized log-likelihood and Schwarz criterion

\begin{tabular}{|c|c|c|c|c|c|}
\hline & \multicolumn{2}{|c|}{$\begin{array}{l}\text { Inflation forecast and real } \\
\text { time quadratic output gap }\end{array}$} & \multicolumn{3}{|c|}{$\begin{array}{c}\text { Inflation forecast and } \\
\text { quad }+\mathrm{GB}+\mathrm{CBO} \text { output gap }\end{array}$} \\
\hline$k$ & $\begin{array}{c}\text { Maximized } \\
\text { log-likelihood }\end{array}$ & $\begin{array}{l}\text { Schwarz } \\
\text { criterion }\end{array}$ & $k$ & $\begin{array}{c}\text { Maximized } \\
\text { log-likelihood }\end{array}$ & $\begin{array}{l}\text { Schwarz } \\
\text { criterion }\end{array}$ \\
\hline 1 & -356.1 & 732.6 & 1 & -351.5 & 723.4 \\
\hline 2 & -311.2 & 658.0 & 2 & -294.3 & 624.2 \\
\hline 3 & -214.3 & 504.9 & 3 & -214.1 & 504.6 \\
\hline 4 & -208.0 & 543.3 & 4 & -200.3 & 528.0 \\
\hline
\end{tabular}

Notes: "Quadratic" in "Real time quadratic output gap" refers to the use of the quadratic trend in the calculation of the output gap, which is the percent deviation of actual real time GDP from the quadratic trend. "Quad+GB+CBO" refers to the output gap from quadratic trend estimates (1965Q4-1986Q4) from the Greenbook (GB) (1987Q1-2007Q4) and from Congressional Budget Office (CBO) potential output estimates (2008Q1-2014Q1).

The parameter estimates of the three-state Markov regime-switching model run on the first data set (real time inflation forecast and quadratic output gaps) and on the second data set (real time inflation forecast and quadratic $+\mathrm{GB}+\mathrm{CBO}$ output gaps) are shown in Tables 2 and 3, respectively. Tables 2 and 3 show quantitatively similar results. For regime 2, the inflation coefficients are between 1 and 1.5 and significant at the $1 \%$ level (1.21 in Table 2 and 1.27 in Table 3 ) and the output gap coefficients are significant at the 5\% level and less than 0.5 (0.27 in Table 2 and 0.14 in Table 3$)$. The constants are negative and significant at the $5 \%$ level $(-0.34$ in Table 2 and -1.22 in Table 3). The results for regime 2 in Tables 1 and 2 show that the inflation forecast coefficients, output gap coefficients, and constants are less than the Taylor rule weights of $1.5,0.5$, and 1.0 , respectively, at the $1 \%$ level of significance. ${ }^{14}$

For regime 3, the inflation forecast coefficients are 1.52 and 1.60 in Tables 2 and 3 , respectively, at the 5\% significance level. These coefficients are close to the weight of 1.5 of the benchmark Taylor-rule regime. The output gap coefficients are -0.05 in Table 2 and -0.08 in Table 3 and insignificant at the $10 \%$ significance level. The constants are 3.14 and 2.39 in Tables 2 and 3, respectively, and significant at the $1 \%$ level. Compared with the Taylor rule, the inflation forecast coefficients are not significantly different from 1.5 at the $10 \%$ level of significance, whereas the coefficients of output gaps are significantly different from 0.5 and the constants are significantly different from one at the $5 \%$ and higher levels of significance. ${ }^{15}$ Because the constants for regime 2 and 3 in both Tables 2 and 3 are significantly different from 1, this suggests that the equilibrium real interest rate and/or the target inflation rate may vary over time.

Tables 2 and 3 also show the conditional variances of the Federal funds rate and the transition probabilities. The results in both tables are quantitatively similar. Table 2 (Table 3 ) shows that conditional variances are $0.48(0.55)$ for the Taylor rule regime, $0.40(0.33)$ for regime 2 , and $1.69(1.57)$ for regime 3 at the $5 \%$ and 
TABLE 2. Parameter estimates and standard errors (in parentheses) for the threestate Markov regime-switching model (sample period: 1973Q3-2014Q1)

\begin{tabular}{lccc}
\hline $\begin{array}{l}\text { Variable } \\
\text { (real-time data) }\end{array}$ & $\begin{array}{c}\text { Regime 1 } \\
\text { (Taylor } \\
\text { rule) }\end{array}$ & $\begin{array}{c}\text { Regime 2 } \\
\text { (low discretionary } \\
\text { regime) }\end{array}$ & $\begin{array}{c}\text { Regime 3 } \\
\text { (high discretionary } \\
\text { regime) }\end{array}$ \\
\hline Constant & 1 & $-0.34^{* *}$ & $3.14^{* * *}$ \\
GDP deflator inflation forecast & 1.5 & $(0.15)$ & $(1.03)$ \\
Real time quadratic output gap & 0.5 & $(0.03)$ & $1.52^{* * * *}$ \\
& & $0.27^{* * *}$ & $(0.17)$ \\
$\sigma_{j}^{2}$ & $0.48^{* * *}$ & $(0.02)$ & -0.05 \\
& $(0.11)$ & $(0.07)$ & $(0.12)$ \\
$p_{1 j}$ & 0.92 & 0.08 & $1.69^{* * *}$ \\
$p_{2 j}$ & 0.05 & 0.94 & $0.79)$ \\
$p_{3 j}$ & 0.04 & 0.00 & 0.00 \\
CPI inflation variability & Average variability for a regime & 0.96 \\
GDP deflator inflation variability & 0.348 & 0.819 & 0.935 \\
Real GDP variability & 0.101 & 0.202 & 0.266 \\
\hline
\end{tabular}

Notes: "Quadratic" in "real time quadratic output gap" refers to the use of the quadratic trend in the calculation of the output gap, which is the percent deviation of the actual real time GDP from the quadratic trend. GDP deflator inflation forecast data are from the Greenbook (1973Q3-1987Q4) and the Survey of Professional Forecasters (SPF) (1988Q1-2014Q1). Data until 2010Q2 are downloaded from https://sites.google.com/site/alexrzhevskyy/files/ data_rules_discretion.zip. We extend to 2014 the data on inflation forecast using data from the SPF and the data on real time quadratic output gap using data on real time GDP calculated following NPP (2013). SPF and real time GDP data are from the Federal Reserve Bank of Philadelphia Website. Quarterly CPI inflation, GDP deflator inflation, and real GDP data are obtained from the International Financial Statistics.

${ }^{* * *},{ }^{* *},{ }^{*} 1 \%, 5 \%$, and $10 \%$ levels of significance, respectively.

higher levels of significance. The results show that the conditional variances of regime 2 are less than the conditional variances of the Taylor rule regime, whereas the conditional variances of regime 3 are greater than the conditional variances of the Taylor rule regime. In addition, Tables 2 and 3 show the estimated transition probabilities $\left(P\left(S_{t}=j \mid S_{t-1}=i\right)=p_{i j}\right)$ that if the Fed is in a particular monetary regime $i$ for a quarter, the Fed will either remain in the same regime $(i=j)$ or switch to another monetary regime $j(i \neq j)$ for the next quarter. In particular, the transition probabilities of remaining in the same regime over two quarters are over $90 \%$ for all three regimes $\left[p_{11}=0.92(0.96), p_{22}=0.94(0.95)\right.$, and $p_{33}=0.96$ (0.97) in Table 2 (Table 3)]. Hence, it is implied that each of the three regimes is persistent, suggesting that the Fed likely follows or deviates from the Taylor rule for several quarters.

The last three rows of Tables 2 and 3 show the average variability of CPI inflation, of GDP deflator inflation, and of real GDP growth for each of the three regimes. The tables clearly show that on the average, the variability of CPI inflation, of GDP deflator inflation, and of real GDP growth in regime 1 (Taylor 
TABLE 3. Parameter estimates and standard errors (in parentheses) for the threestate Markov regime-switching model (sample period: 1973Q3-2014Q1)

\begin{tabular}{lccc}
\hline $\begin{array}{l}\text { Variable } \\
\text { (real-time data) }\end{array}$ & $\begin{array}{c}\text { Regime } 1 \\
\text { (Taylor } \\
\text { rule) }\end{array}$ & $\begin{array}{c}\text { Regime 2 } \\
\text { (low discretionary } \\
\text { regime) }\end{array}$ & $\begin{array}{c}\text { Regime 3 } \\
\text { (high discretionary } \\
\text { regime) }\end{array}$ \\
\hline Constant & 1 & $-1.22^{* * *}$ & $2.39^{* * *}$ \\
GDP deflator Inflation forecast & 1.5 & $(0.34)$ & $(0.72)$ \\
& & $\left(0.27^{* * *}\right.$ & $1.60^{* * *}$ \\
Output gap (Quad+GB+CBO) & 0.5 & $0.14^{* *}$ & $(0.13)$ \\
& & $(0.04)$ & -0.08 \\
$\sigma_{j}^{2}$ & $0.55^{* * *}$ & $0.33^{* * *}$ & $(0.10)$ \\
$p_{1 j}$ & $(0.09)$ & $(0.08)$ & $1.57^{* * *}$ \\
$p_{2 j}$ & 0.96 & 0.04 & $(0.50)$ \\
$p_{3 j}$ & 0.03 & 0.95 & 0.00 \\
CPI inflation variability & 0.03 & 0.00 & 0.02 \\
GDP deflator inflation variability & 0.091 & 0.292 & 0.97 \\
Real GDP variability & 0.821 & 1.297 & 0.781 \\
\hline
\end{tabular}

Notes: "Quad+GB+CBO" refers to the output gap from quadratic trend estimates (1965Q4-1986Q4), from the Greenbook (GB) (1987Q1-2007Q4) and from Congressional Budget Office (CBO) potential output estimates (2008Q1-2010Q2). GDP deflator inflation forecast data are from the Greenbook (1973Q3-1987Q4) and the SPF (1988Q1-2014Q1). Data until 2010Q2 are downloaded from https://sites.google.com/site/alexrzhevskyy/ files/data_rules_discretion.zip. We extend to 2014 the data on inflation forecast using data from the SPF and the data on real time quadratic+Greenbook+CBO output gap, using data on potential real GDP from the CBO Website and real time GDP from the Federal Reserve Bank of Philadelphia Website, calculated following NikoloskoRzhevskyy and Papell (2013). Quarterly CPI inflation, GDP deflator inflation, and real GDP data are obtained from the International Financial Statistics.

***, ${ }^{* *},{ }^{*} 1 \%, 5 \%$, and $10 \%$ levels of significance, respectively.

rule regime) are less than in regime 2 or regime 3. Hence, the Taylor rule regime may be associated with lower variability of inflation and real GDP growth, whereas the discretionary regimes may be associated with higher variability of inflation and output growth.

We calculate the implied interest rates based on the fitted model for the three regimes and plot them in Figure 1 for the first data set and Figure 2 for the second data set, where the light solid line, the dotted line, and the dashed line represent the interest rates implied by the Taylor rule regime (regime 1), the low discretionary regime (regime 2), and the high discretionary regime (regime 3 ), respectively. Figures 1 and 2 show that the implied interest rate of regime 2 is less than the implied interest rate of the Taylor rule regime (except for three to four quarters in 2009), whereas the implied interest rate of regime 3 is greater than the implied interest rate of the Taylor rule regime. This suggests that when the Fed deviates from the Taylor rule, the interest rate could be expected to be either lower or higher than the rate implied by the Taylor rule. 


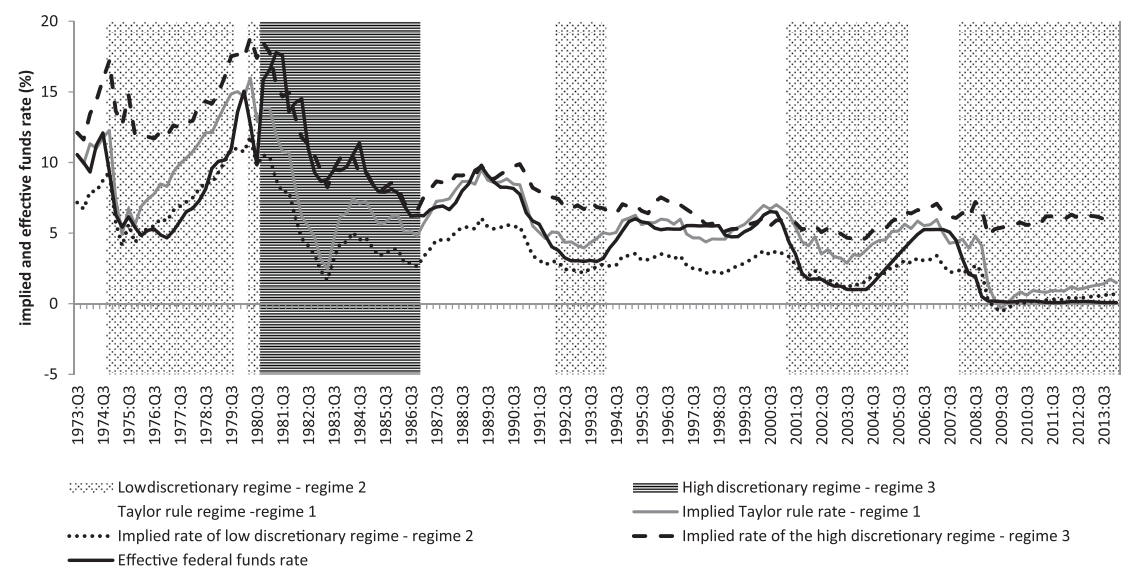

FIGURE 1. Conditional means and fund rate based on three-Markov regime switching model (real time GDP deflator Inflation forecast and real time quadratic output gap).

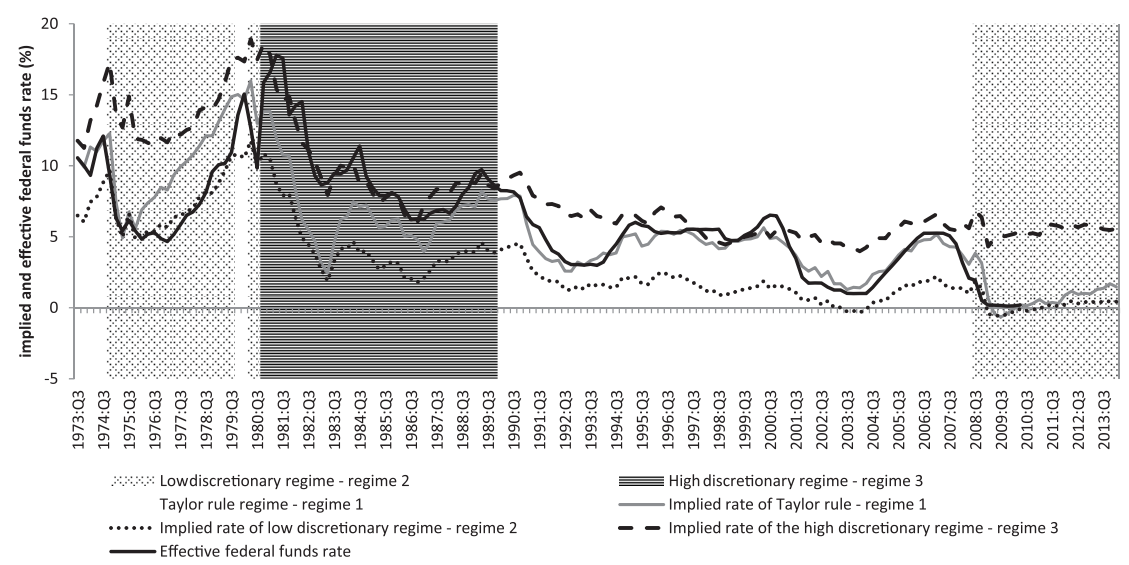

FIGURE 2. Conditional means on three-state Markov regime switching model (inflation forecast from Greenbook \& SPF and output gap from quadratic trend, Greenbook, and CBO).

Because we find lower (higher) conditional volatility and implied interest rates in regime 2 (regime 3 ) than in the Taylor regime (regime 1), we refer to regime 2 and regime 3 as "low" and "high" discretionary regimes, respectively.

Figures 1 and 2 also show the classifications of the three regimes, based on the highest estimated smoothing probability among the three regimes. The unshaded areas correspond to the Taylor rule regime, whereas the shaded areas correspond to the regimes that deviate from the rule, with the light (dark) shaded areas indicating regime 2 (regime 3). As mentioned earlier, the implied interest rates of regimes 1,2 , and 3 are indicated by the dashed-and-dotted line, the dotted line, and the 


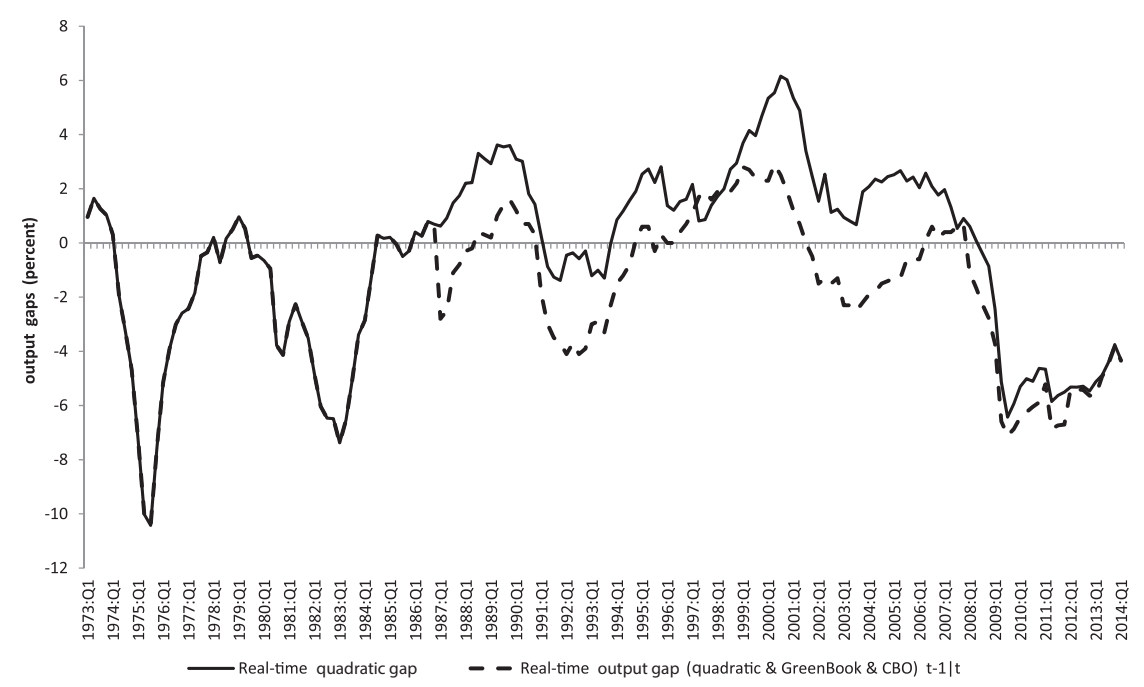

FIGURE 3. Output gaps.

dashed line, respectively. In addition, the effective federal funds rate is indicated by the solid line.

Figures 1 and 2 show similar results from 1973Q3 to 1986Q4 and 2008Q2 to 2014Q1. Both figures show that regime 1 (Taylor rule) holds during 1973Q31974Q3 and 1979Q4-1980Q1; regime 2 (low discretionary regime) holds during 1974Q4-1979Q3, 1980Q2-1980Q3, and 2008Q1-2014Q1; and regime 3 (high discretionary regime) holds during 1980Q4-1986Q4.

The differences between Figures 1 and 2 occur from 1987Q1 to 2007Q4. Figure 1 shows that regime 1 or the Taylor rule holds during 1987Q1-1992Q1 and 2006Q1- 2007Q1 and regime 2 or the low discretionary regime holds during 1992Q2-1994Q1 and 2001Q2-2005Q4. In contrast, Figure 2 shows that the high discretionary regime (regime 3) extends to 1989Q4 (from 1980Q4), followed by a period in which the Taylor regime or regime 1 holds from 1990Q1 to 2008Q1. These differences also coincide with the use of output gaps estimated from the quadratic trend in Figure 1 and of output gaps estimated from the Greenbook data set in Figure 2. We plot the quadratic output gaps and quadratic $+\mathrm{GB}+\mathrm{CBO}$ output gaps in Figure 3, which shows that the output gaps measured from the quadratic trend are greater than the output gaps from the Greenbook data set. Hence, this leads to estimates of the interest rate, implied by the Taylor rule to be greater in Figure 1 than in Figure 2 from 1987Q1 to 2007Q4.

Although the differences between Figures 1 and 2 are in the periods 1987Q1 to 2007Q4, we note that before 2007Q4, the changes in regimes in the two figures do not coincide with 1986Q4-1987Q1, in which the data on quadratic output gaps (1965Q4-1986Q4) were combined with the data on Greenbook output gaps (1987Q1-2007Q4). However, the regime switch from the Taylor rule regime 
(regime 1) to the low discretionary regime (regime 2) occurred in 2007Q4-2008Q1 when the inflation forecast data from Greenbook and SPF and output gaps data from the Greenbook and the $\mathrm{CBO}$ were combined to construct the respective series until 2014Q1.

The implications of the differences in Figures 1 and 2 for 1990Q1-2008Q1 are that Figure 2 shows that the Fed followed the Taylor rule if the implied rates are calculated using GDP inflation forecast and output gaps from the Greenbook data set, but Figure 1 shows two periods of low discretionary regimes during 1992Q2-1994Q1 and 2001Q2-2005Q4. Therefore, the results of the three-state Markov regime-switching model with Greenbook data (Figure 2) would show support for Bernanke's (2010) argument that the Fed followed the Taylor rule in the mid-2000 rather than Taylor's (2008) argument that the Fed deviated from the Taylor rule and caused the housing price bubble. The reverse would be the case if the inflation forecast and quadratic output gaps (Figure 1) were used as regressors in the Markov regime-switching model.

As mentioned above, both Figures 1 and 2 show that the low discretionary regime holds from 2008Q2 to 2014Q1. In both cases, the implied rates of the low discretionary regime and the Taylor regime from 2009Q1 to 2014Q1 may be negative from one to eight quarters, but they are not significantly different from zero. $^{16}$

\section{CONCLUSIONS}

We examine U.S. monetary policies from 1973 to 2014 using a $k$-state Markov regime switching model in which the number of regimes is determined using the Schwarz (1978) criterion and the periods of the regimes are endogenously determined from the data. The model presents a unified and simplified framework with results consistent with the experience of the United States in the Fed's conduct of monetary policies. Using the Taylor rule as a benchmark, we find that the low discretionary regime holds in the 1970s, which could be interpreted as too stimulating even though the low discretionary regime has a coefficient on the inflation forecast greater than one. This finding is consistent with NikolskoRzhevskyy and Papell's (2012) conclusion that the Taylor rule was destabilizing and too stimulating, contrary to Orphanides's (2003a, 2003b) claim that the Fed followed a stabilizing Taylor rule in the 1970s.

We also find that the high discretionary regime holds in the 1980s, which could be considered too restrictive, using the Taylor rule as a benchmark. Our findings from the mid-1990s to 2008 differ depending on the measures of the output gap. Using quadratic output gaps, the high discretionary regime that began in 1980 ended in 1986. From 1987 to 2008, the Taylor rule regime mostly holds, except from 1991 to 1992 and from 2001 to 2005, when the low discretionary regime holds. These findings support Taylor's (2008) argument that the Fed deviated from the Taylor rule and caused the housing price bubble. However, using the output gaps from the Federal Reserve's Greenbook data set, we find that the high 
discretionary regime ended in 1989, followed by the Taylor rule regime until 2008. Therefore, the Fed's own estimates of the output gaps support Bernanke's (2010) contention that the Fed followed the Taylor rule in the 2000s and could not have caused the housing price bubble. Hence, we show that the Taylor (2008) and the Bernanke (2010) disagreement could be due not only to differences in measures of inflation or the use of either inflation or inflation forecast as discussed in Bernanke (2010) and Nikolsko-Rzhevskyy and Papell (2013), but also to differences in the estimates of the output gaps.

For both measures of the output gaps, we find that the low discretionary regime holds from 2008 to 2014 , with implied interest rates negative for up to eight quarters but not significantly different from zero. Hence, neither the low discretionary regime nor the Taylor rule offers justification for the Fed's quantitative easing conducted by the Fed during the 2008 financial crisis. These findings are consistent with the conclusions of Nikolsko-Rzhevskyy and Papell (2013).

We also observe that the variability of CPI inflation, GDP deflator inflation, and real GDP growth are lower during the Taylor regime than during the two discretionary regimes. However, our coefficient estimates of the discretionary regimes (regimes 2 and 3 ) show that the coefficients of inflation forecast in the Taylor rule specification to be greater than one. This implies that if the interest rates were valid targets of Fed's policies, interest rates responded more than one-for-one to the inflation forecast, so that the Taylor principles held even in periods during the low and high discretionary regimes. Therefore, our results show that inflation variability could be substantially higher even when discretionary monetary policy seemingly adhered to the Taylor principle.

\section{NOTES}

1. Murray et al. (2015) use data on inflation forecasts taken from the Fed's Greenbook (GB) data set updated with data from the Survey of Professional Forecasters (SPF) and two measures of real time output gaps: the first measure is taken from Orphanides (2004), based on Council of Economic Advisers (CEA) estimates updated with output gaps calculated using Congressional Budget Office (CBO) potential output, and the second measure is calculated by taking the deviations of real time real GNP/GDP from its quadratic trend.

2. NPP (2013) use real time inflation rates calculated as the year-on-year change of the GDP deflator and real time output gaps calculated as percentage deviations from the quadratic trend of real GDP. In addition to the two-state Markov regime-switching model, they examine endogenously the periods of the occurrence of high and low deviations from the Taylor rule using linear regressions with multiple breaks.

3. We are aware only of Nikolsko-Rzhevskyy and Papell (2013), who studied the post-2008 financial crisis period (2009-2011) in the context of the Taylor rule. They compare specifications of the original and modified versions of the Taylor rule during various recessions in the past decades, including the post-2008 crisis.

4. Our paper differs from NPP (2013) as follows: 1. Our Markov regime-switching model endogenously determines the number of different monetary regimes, $k$, based on the Schwarz criterion, with $k$ determined at three and the first regime restricted to the specification of the Taylor rule. In contrast, NPP's Markov regime-switching model assumes two monetary regimes, defined as large and small deviations, measured by the absolute difference between the Fed funds rate and the rate implied by the 
Taylor rule. 2. Our model allows for the different coefficients of inflation and output gaps and for the different conditional variances of the federal funds rates among different monetary regimes.

5. Real GDP volatility and inflation volatility are often considered in examining the Great Moderation in G-7 countries from the 1980s to 2007. Although the Great Moderation is beyond the scope of the paper, we would like to examine if and how variability in real GDP and in inflation are likely associated with a particular monetary regime. Clark (2009) and Benati and Surico (2009) give a short review of the literature on the Great Moderation.

6. Tests for the number of regimes under Markov regime-switching models are typically difficult to carry out, because they do not follow standard distributions. For instance, under the null of a single regime versus the alternative of two regimes, the parameters of the alternative regime are not identified. This means that conventional likelihood ratio tests are not asymptotically chi-square distributed. Several researchers have addressed this issue for certain types of Markov regime-switching models, particularly for testing two regimes, such as Garcia (1998). However, our study considers Markov regime-switching models with more than two regimes, and as far as we know, there are no available tests for models with more than two regimes. In contrast, model selection criteria such as the Schwarz criterion are commonly used in various applications to estimate the number of regimes for Markov regime-switching models [e.g., Wang and Puterman (1999); Haas et al. (2004)]. As pointed out by Rydén (1995), the Schwarz criterion in the limit never underestimates the number of regimes in Markov regime-switching models.

7. Revised real GDP growth and changes in CPI are used as measures of output growth and inflation, respectively, in the literature on the Great Moderation. As a comparison, we also consider revised GDP deflator inflation to measure inflation variability, consistent with our measure of inflation using real time data.

8. The Website https://sites.google.com/site/alexrzhevskyy/files/data_rules_discretion.zip is mentioned in NPP (2013). The data set has quarterly data from 1965 Q4 to 2010 Q2 with six measures of real-time output gaps. namely quadratic gap, linear gap, window output gap, HP gap, and two output gap measures that augment the Federal Reserve Bank's Greenbook data set, which covers only 1987 Q1 to 2007 Q4. It also has data on real-time GDP deflator inflation, GDP deflator inflation forecast, and effective federal funds rate. The original data used in the construction of the real time output gaps, real time inflation, and real time inflation forecast are from the Federal Reserve Bank of Philadelphia, and the effective federal funds rates are from the Federal Reserve Bank of St Louis.

9. Two other popular measures of the output gaps use linear detrending and the Hodrick-Prescott (HP) filter. However, NPP (2013) recommend using the quadratic output gaps instead of "linear detrending" output gaps and "HP filter" output gaps. Their recommendation is based on their assessment of the three measures of the output gaps, which considered the real time unemployment rates and the estimates of the natural rate of unemployment and of the Okun's law coefficient for the United States.

10. Details of the construction of real time output gaps at the Nikolosko-Rzhevskyy Website are discussed in NPP (2013) (output gap estimates using quadratic trends) and Nikolosko-Rzhevskyy and Papell (2013) (output gap estimates from the Greenbook data set augmented with estimates using potential output data from the $\mathrm{CBO}$ ).

11. The construction of the real time GDP deflator inflation forecast is discussed in Murray et al. (2015). This series matches the four-quarter averages of median growth of the GDP deflator forecast from the SPF database accessed from the Federal Reserve Bank of Philadelphia Website. Data on real time GDP deflator inflation forecasts are available without missing observations from 1973Q3 onwards.

12. This possibility is pointed out by NPP (2013).

13. Among others, Nikolsko-Rzhevskyy and Papell (2013) and Murray et al. (2015) use inflation forecasts and Greenbook output gaps in examining Taylor rules.

14. We use the $t$-test to determine if the coefficients of regime 2 are significantly different from the corresponding weights suggested by the Taylor rule as follows: (coefficient of the variable in regime 2 - corresponding weight of the variable in the Taylor rule)/(standard error of coefficient of the variable in regime 2). The standard errors of the weights of the Taylor rule are assumed to be zero. For a comparison with coefficients of regime 2 and the Taylor rule regime in Table 2, the $t$-statistics for 
inflation forecast coefficient, output gap coefficient, and the constant of regime 2 compared with 1.5, 0.5 and 1.0 are $-9.67,-11.5$, and -8.93 , respectively. From Table 3 for regime 2 , the $t$-statistics for inflation coefficient, the output gap coefficient, and the constant compared with 1.5, 0.5 and 1 are -5.4 , -9 , and -6.52 , respectively. The critical values are $\pm 1.645, \pm 1.96$, and \pm 2.326 at the $10 \%, 5 \%$, and $1 \%$ levels of significance, respectively.

15. We also use the $t$-test in ascertaining if the coefficients of regime 3 are significantly different from the weights of 1.5, 0.5, and 1 of the Taylor rule. For regime 3 versus the Taylor rule regime of Table 2, the $t$-statistics for the inflation forecast coefficient, the output gap coefficient, and the constant compared with $1.5,0.5$, and 1 are $0.125,-4.58$, and 2.08 , respectively. For regime 3 versus the Taylor rule regime of Table 3, the $t$-statistics for the inflation coefficient, the output gap coefficient, and the constant compared with $1.5,0.5$, and 1 are $0.76,-5.8$, and 1.93 , respectively. The critical values are $\pm 1.645, \pm 1.96$, and \pm 2.326 at the $10 \%, 5 \%$, and $1 \%$ levels of significance, respectively.

16. From Figure 1 and Table 2, the implied rates of the lower discretionary regime from 2009Q1 to $2014 \mathrm{Q} 1$ are $-0.44,-0.55,-0.58,-0.45,-0.28,-0.09,-0.22,-0.12,-0.08,0.15,0.18,0.11,0.23$, $0.47,0.30,0.41,0.38,0.44,0.38,0.47$, and 0.43 , with a standard error of 0.63 , and the implied rates of the Taylor rule are $0.66,-0.43,-0.65,-0.42,-0.07,0.22,0.14,0.31,0.58,0.30,0.38,0.30,0.89,1.16$, $0.95,1.02,0.98,1.29,1.38,1.70$, and 1.47, with a standard error of 0.69 . From Figure 2 and Table 3, the implied rates of the lower discretionary regime from 2009 Q1 to 2010 Q2 are $0.22,-0.25,-0.56$, $-0.35,-0.06,0.17,0.00,0.20,0.14,0.25,0.33,0.29,0.28,0.51,0.36,0.44,0.50,0.54,0.55,0.73$, and 0.61 , with a standard error of 0.57 , and the implied rates of the Taylor rule are $1.31,0.30,-0.30,0.05$, $0.50,0.83,0.61,0.93,0.86,0.80,0.93,0.90,0.92,1.21,1.02,1.10,1.23,1.32,1.41,1.73$, and 1.49, with a standard error of 0.74 .

\section{REFERENCES}

Benati, Luca, and Paulo Surico (2009) VAR analysis and the Great Moderation. American Economic Review 99, 1636-1652.

Bernanke, Ben S. (2010) Monetary Policy and the Housing Bubble. Speech delivered at the American Economic Association Meetings, January 3.

Boivin, Jean (2006) Has U.S. monetary policy changed? Evidence from drifting coefficients and real-time data. Journal of Money, Credit and Banking 38, 1149-1179.

Castelnuovo, Efrem, Luciano Greco, and Davide Raggi (2014) Policy rules, regime switches, and trend inflation: An empirical investigation for the United States. Macroeconomic Dynamics 18, 920-942.

Clarida, Richard, Jordi Gali, and Mark Gertler (2000) Monetary policy rules and macroeconomic stability: Evidence and some theory. Quarterly Journal of Economics 115, 147-180.

Clark, Todd E. (2009) Is the Great Moderation over? An empirical analysis. Economic Review 4, 5-42.

Davig, Troy and Eric M. Leeper (2006) Fluctuating macro policies and the fiscal theory. In Daron Acemoglu, Kenneth Rogoff, and Michael Woodford (eds.), NBER Macroeconomics Annual 2006, pp. 345-377. Cambridge, MA: MIT Press.

Davig, Troy, and Eric M. Leeper (2011) Monetary-fiscal policy interactions and fiscal stimulus. European Economic Review 55, 211-227.

Garcia, René (1998) Asymptotic null distribution of the likelihood ratio test in Markov switching models. International Economic Review 39, 763-788.

Haas, Markus, Stefan Mittnik, and Mark Paolella (2004) A new approach to Markov switching GARCH models. Journal of Financial Econometrics 4, 493-530.

Hamilton, James D. (1994) Time-Series Analysis. Princeton, NJ: Princeton University Press.

Kim, Chang-Jin and Charles R. Nelson (2006) Estimation of a forward-looking monetary policy rule: A time-varying parameter model using ex post data. Journal of Monetary Economics 53, 1949-1966.

Leroux, Brian G. (1992) Consistent estimation of a mixing distribution. Annals of Statistics 20, 13501360.

Murray, Christian, Alex Nikolsko-Rzhevskyy, and David H. Papell (2015) Markov switching and the Taylor principle. Macroeconomic Dynamics 19, 913-930. 
Nikolsko-Rzhevskyy, Alex and David H. Papell (2012) Taylor rules and the Great Inflation. Journal of Macroeconomics 34, 903-918.

Nikolsko-Rzhevskyy, Alex and David H. Papell (2013) Taylor's rule versus Taylor rules. International Finance 16, 71-93.

Nikolsko-Rzhevskyy, Alex, David H. Papell, and Ruxandra Prodan (2013) (Taylor) Rules versus Discretion in U.S. Monetary Policy. Working paper, Lehigh University. Available at SSRN: http://ssrn.com/abstract=2294990.

Orphanides, Athanasios (2003a) Historical monetary policy analysis and the Taylor rule. Journal of Monetary Economics 50, 983-1022.

Orphanides, Athanasios (2003b) The quest for prosperity without inflation. Journal of Monetary Economics 50, 633-663.

Orphanides, Athanasios (2004) Monetary policy rules, macroeconomic stability, and inflation: A view from the trenches. Journal of Money, Credit and Banking 36, 151-175.

Rydén, Tobias (1995) Estimating the order of hidden Markov models. Statistics 26, 345-354.

Schwarz, Gideon (1978) Estimating the dimension of a model. Annals of Statistics 6, 461-464.

Taylor, John B. (1993) Discretion versus policy rules in practice. Carnegie Rochester Conference Series on Public Policy 39, 195-214.

Taylor, John B. (1999) A historical analysis of monetary policy rules. In John Taylor (ed.), Monetary Policy Rules, pp. 319-347. Chicago: University of Chicago Press.

Taylor, John B. (2008) The Costs and Benefits of Deviating from the Systematic Component of Monetary Policy. Keynote address at the Federal Reserve Bank of San Francisco Conference on Monetary Policy and Asset Markets, February 22.

Wang, Peiming and Martin L. Puterman (1999) Markov Poisson regression models for discrete time series. Journal of Applied Statistics 26, 855-869. 